\title{
Repeat testing for chlamydia trachomatis, a "safe approach" to unsafe sex? a qualitative exploration among youth in Stockholm
}

\author{
Anna Nielsen ${ }^{1 *} \mathbb{D}$, Ayesha De Costa ${ }^{2}$, Kristina Gemzell Danielsson ${ }^{1}$ and Mariano Salazar ${ }^{2}$
}

\begin{abstract}
Background: Chlamydia trachomatis testing is offered to youth in Sweden, through a network of Youth Health Clinics, free at the point of care, in an attempt to bring down the prevalence and incidence of the infection. Nevertheless, infections rates have continued to rise during the past two decades and re-testing rates among youth for Chlamydia trachomatis has been reported to be high in Stockholm County. A few literature reports suggest that testing for sexually transmitted infections and the test result itself can have an undesirable impact on the sexual behaviour for the individual, i.e. increase sexual risk-taking.

Methods: This qualitative study aimed to explore the motives for repeated testing for Chlamydia trachomatis among youth using the services of the Youth Health Clinics in Stockholm, and how testing affects their subsequent risk-taking. We interviewed 15 repeat testers aging 18-22 years.

Results: Our main findings were that the fear of social stigma related to infecting a peer was a major driver of the re-testing process. The repetitive testing process, the test result, and the encounter with personnel did not decrease sexual risk-taking among this group.

Conclusions: While testing and treatment services are an important part of Chlamydia trachomatis prevention it must not take the focus away from primary prevention strategies. Testing should be encouraged, but not to the exclusion of risk reduction measures. The testing services must be complemented with stronger emphasis on safe sex, especially for those who attend the clinics repeatedly, otherwise the easy accessible testing services risk counteracting its own purpose. Future research should focus on developing and evaluating youth appropriate interventions to increase condom use, taking into consideration factors which youth perceive as important to drive this behaviour change.
\end{abstract}

Keywords: Chlamydia trachomatis, Youth, Repeat testing, Stigma, Sexual health, Sweden, Sexual behaviour, Health care utilization

\section{Background}

Chlamydia trachomatis (C.trachomatis) is the most commonly reported sexually transmitted infection (STI) in Sweden and worldwide, most commonly affecting young adults $[1,2]$. In an attempt to control the epidemic, several countries have introduced population-based screening programs or opportunistic screening programs [1].

\footnotetext{
* Correspondence: anna.nielsen.1@ki.se

'Department of Women's and Children's Health K6, Karolinska University Hospital Solna, 17176 Stockholm, Sweden

Full list of author information is available at the end of the article
}

In Sweden, an opportunistic screening approach, which began in the 1980s, is available across the country [3].

The most effective way to tackle the epidemic of C.trachomatis is still being debated, and different guidelines on C.trachomatis screening exist in different settings [4]. For example, in the United States re-testing for C.trachomatis 3 months after diagnosis is recommended, [5]. In the United Kingdom, the National C.trachomatis Screening Program aims to test people under the age of 25 once a year [6].

The Swedish opportunistic screening program has been held up as a model program [7]. Approximately 
500,000 C.trachomatis tests are performed in the country per year (2011-2015) with an overall positivity rate of six to $7 \%$ [2]. Women account for $57 \%$ of all reported cases. The median age for infected individuals is 22 years for women and 24 years for men [2]. Guided by national laws and regulations $[8,9]$, regional policies control the preventive work in the different County Councils in Sweden [10]. Repeat testing after an infection is not official policy in Stockholm County [10].

Nevertheless, repeated testing for C.trachomatis is relatively common behaviour among youth living in Stockholm County. In a recent study, we found that $42 \%$ of youth using the testing services at the Youth Health Clinics (YHC) in Stockholm re-tested for C.trachomatis during a 3 year period [11]. The repeat testers in our study tested between two to 19 times over the study period [11]. Re-testing was associated with being female, a previous positive test and living in a high- or middleincome area of Stockholm. Furthermore, we found high rates of C.trachomatis among repeat testers both at baseline and at repeat tests which suggests the possibility that this group might be continuing to engage in unsafe sexual practices [11]. However, the reasons for repeat C.trachomatis testing on an individual level are still unknown.

There is some evidence in the literature which suggests that a positive test result for a STI might affect sexual risk taking promoting a more protective disposition, at least in the short term [12, 13]. A negative STI test result, on the other hand, seems to have no effect on subsequent risk taking [12]. Studies focusing on HIV testing indicate that a negative test result can have an undesirable effect on behavioral changes, i.e. adopting more risky sexual practices [14-17].

Re-testing for $C$. trachomatis can have positive consequences for people and the society; i.e. positive cases are detected and treated. Thus, comprehensive testing services are therefore important. However, re-testing can also have negative consequences for health systems and individuals. For individuals, repeated testing might be a consequence of continuous risky sexual behaviour that exposes them not only to C.trachomatis infections but to other more serious infections such as gonorrhoea, HPV, syphilis, and HIV.

For health systems, repeated testing without long term behavioural change might not reduce C.trachomatis incidence and therefore can result in an inefficient use of resources. In addition, repeated infections and subsequent antibiotic use contributes to increase antibiotic resistance in this population [18]. Evidence from Sweden has shown that C.trachomatis testing services are repeatedly used by a proportion young adults [11], who, in spite of their constant exposure to testing services, continue to exhibit risky sexual behaviours. This, together with the reported high rates of C.trachomatis in Stockholm County [2],might indicate that health care resources have not been effectively used to reduce the incidence of C.trachomatis infections in this setting.

\section{Objectives and rationale}

In order to strengthen the opportunistic screening program in Sweden it is important to explore the reasons behind the high C.trachomatis re-testing figures previously reported in this setting [11]. Thus, this qualitative study aims to explore the motives for repeat testing for C.trachomatis among youth using the services of the Youth Health Clinics in Stockholm, and how testing affects their sexual risk-taking. The results of this study will allow the C.trachomatis screening program to design and implement appropriate interventions to work with youth retesting frequently and take steps make the program more effective. In addition, the lessons learned from our study might be helpful to other screening programs dealing with high re-testing rates.

\section{Theoretical framework}

We have chosen the Andersen's Model of Health Service Utilization as theoretical framework for this study [19]. In the model, usage of health services is determined by three dynamics: predisposing factors, enabling factors, and need. Predisposing factors include characteristics such as gender, age, ethnicity, and health beliefs. Enabling factors include family support, income, and accessibility to health care in the community. Need represents both perceived and actual need for health care services [20].

The model used in this paper was adapted from Andersen in 1995; the phase four model [20]. This model describes a number of interacting factors influencing health service utilization. These factors are: 1. The Environment (health care system and external environment such as physical, political and economic environment), 2. Population characteristics as mentioned above (predisposing factors, enabling factors and need). 3. Health Behaviour (personal health practices and use of the health care system) and 4. Outcome (perceived health status, evaluated health status and customer satisfaction). The model also recognizes that outcome and consumer satisfaction affects the predisposing factors, the perceived need and the use of health services [20].

\section{Methods}

\section{Setting}

The study was conducted at the YHC in Stockholm County, Sweden. Stockholm County is spread over an area of $6488 \mathrm{~km}^{2}$, and contains both urban and rural areas. The total population is approximately 2.2 million 
and youth (15-24 year old) account for approximately $11.6 \%$ of the population [21].

Stockholm has one of the highest C.trachomatis infection rates in the country with 459 cases/100,000 inhabitants in 2015 [2]. In 2015, 10,144 cases of C.trachomatis were identified in the county representing a $7 \%$ increase from the previous year. Most cases were found in the age group 20-24 (37\%) years and more than half (54\%) were in women [2]. Approximately 40\% (2012) of all positive tests in Stockholm were carried out at the YHC [22].

\section{Youth health clinics}

Sweden is a high income country with universal health care provided by the state [23]. Health care for young people is free at the YHC. In 1970 the first YHC was launched in Sweden. Sexual health and development was and is the main focus of the YHC [24]. The staff comprise of nurse/midwives, behavioural therapists, social workers and physicians. In the whole country there are approximately 220 clinics with 33 located in Stockholm County $[25,26]$.

The target age for the YHC ranges from 12 to 23 years old. The clinics are involved both in primary prevention of STI, (i.e. sexual education to school classes, counselling of clients and condom information/distribution), and secondary prevention (i.e. testing and treatment services). Opportunistic screening is incorporated into its services. In 2014, 113,000 visits were made by approximately 56,000 unique visitors to the YHC in Stockholm [26].Approximately 40,000 C.trachomatis tests are performed in the YHC in Stockholm each year [11].

\section{Participant selection}

Participants were recruited using a non-probabilistic stratified sample [27]. Respondents for interviews (youth who came to the clinic) were selected purposefully, so that both sexes and persons from different socio-economic zones of Stockholm were represented in the sample.

The participants were initially approached when attending the $\mathrm{YHC}$ for a C.trachomatis test. A person who was identified as a repeat tester (tested more than once during a 6 month period) by the clinic midwife was informed briefly about the study. If the young person showed interest in participating in the study they were asked for permission to be contacted by a member of the research team for more detailed information. If such permission was given, then the young person was contacted by the first author (AN), who provided oral and written information about the purpose of the study, answered any questions or clarifications and invited the young person to participate in an in-depth interview.
In total we gathered data from 15 in-depth interviews (eight female and seven male) from eight different YHC situated in different areas of Stockholm (inner city and suburbs). Saturation was reached after 15 interviews. The age of the participants ranged from 18 to 22 years. All participants were unmarried and no one was currently in a steady relationship. All participants except one had finished upper secondary school. Most interviewees were living with their family (9/15). Equally many participants were studying at university as those employed. Three participants were looking for a job. In all interviews the participants referred to partners of the opposite sex while discussing sexual practices.

\section{Data collection}

The in-depth interviews were conducted at a quiet location chosen by the participant. A trained qualitative researcher, the first author (AN) conducted all interviews, which took from 33 to $55 \mathrm{~min}$. The interviews were conducted in Swedish and were recorded using a mobile phone device. The recordings where sent to a computer via e-mail, downloaded and saved on a password protected computer. The interviews were transcribed verbatim in Swedish. The interviews were conducted between April 2015 and August 2016.

\section{Interview guide}

A semi-structured interview guide with open ended questions was used to gather the data (Additional file 1). Aspects that were explored included: youth perception of visiting the clinic; their experiences testing and retesting for C.trachomatis, their concepts of a safe/unsafe sexual behavior and their perceptions of the consequences of being infected with C.trachomatis.

Follow-up, probing, and interpretive questions were used to further explore and clarify topics that were identified during the interview [28, 29]. In order to expand our understanding of the phenomenon under study, new topics that arose from the previous interviews where included in the subsequent interviews.

\section{Data analysis}

We analyzed the data using a constructivist grounded theory approach as described by Charmaz [30]. The data collection and analysis were conducted in parallel. This allowed us to use an abductive analytical process to create emerging hypothesis based on the text and to explore them in-depth in the following interviews [30].

The process of analyzing the data began by first reading the interview transcripts and then conducting a lineby-line open coding of the data. Coding for actions was done as it facilitates the description of what is happening within the data. The codes identified in the different interviews were constantly compared with each other to 
reach a higher level of abstraction. This was done in parallel by two researchers and conceptual categories were created through a process of argumentation and consensus.

Memo-writing was done throughout the process of data collections to narrow the scope of the different categories, to record emerging ideas about the relationships between categories and to identify the core category. Finally, the categories were linked together in a theoretical model. Data was coded in English using OpenCode 3.4 a free software developed by Umeå University [31].

\section{Results}

Our constructivist grounded theory analysis showed that re-testing for C.trachomatis is a process (Fig. 1) that contains four categories describing the different steps involved in this behavior. The categories (and their corresponding subcategories) were: 1) Negotiating unsafe sex (alcohol use, obstacles of condom use, trust and C.trachomatis not a serious infection; 2) Testing -"better safe than sorry" (anxiety due to social stigma related to spreading the infection and anxiety due to possible long-term medical consequences) 3) Negative test result - false security and 4) Positive test result - a "quick fix". In the following we will present each category, as well as, the health care service factors facilitating the re-testing process.

\section{Negotiating unsafe sex}

Four interacting sub-categories that promoted unprotected sex were identified. These sub-categories were; alcohol use; obstacles to condom use; trust in sexual partner, and; C.trachomatis not a serious infection. While negotiating unprotected sex alcohol stood out as an important factor increasing its likelihood and decreasing the chance of making sound decisions in the heat of the moment. Both the young men and the young women in our data talked about the obstacles of condom use. Sex with a condom was not considered as good as sex without a condom. Strong views on the subject were expressed;

"I rather have no sex than have sex with a condom; I always choose pleasure before safety" (Interview 1, 20 year old man).

Trusting someone to have unprotected sex with was a process where risk and rewards were constantly being evaluated. Condom use depended on how safe the other person was perceived to be, thus it became a negotiation with oneself whether to choose to trust someone and make the sexual encounter more pleasurable (without condoms) or whether to avoid unprotected sex.

The informants used several strategies to assess their potential sexual partner's trustworthiness. For example, youth tended to ask their partner about STI status, and men additionally asked about the use of other contraceptives. In addition, trust was constructed on how well one knew a prospective sexual partner. To trust a friend or a person belonging to the same network was considered reasonably safe. However, with a casual recent acquaintance trust was built on people's appearances including their clothing, their behaviour and how much they were attracted to each other. Conversely, it was also expressed that wanting to trust was a way of finding excuses for ones behaviour.

"Trust is very important. At least from my perspective. Those times I had unprotected sex I like asked the girl if she had (was using) any contraceptives and it also happens that you ask about when was the last time you tested. Well, then you just trust that person's word. And

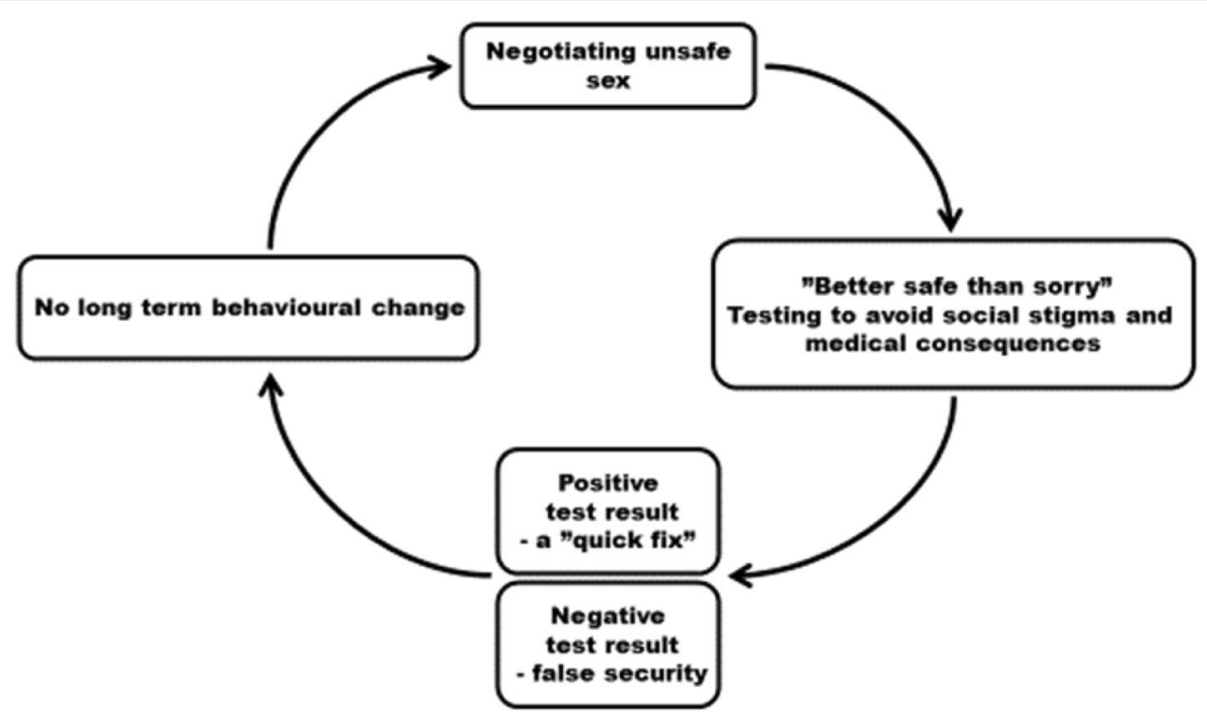

Fig. 1 The cyclic process of testing for C.trachomatis 
that could be someone you just dragged home after a night out. Ah, it is not so much that you can really trust in such scenario but you choose to trust just to make that moment pleasurable and because you are not used to using a condom". (Interview 5, 21 years old man).

Whilst negotiating risk inherent in unprotected sex, with regard to C.trachomatis infection it became clear that C.trachomatis was not considered a serious infection. C.trachomatis was looked upon as 'the most preferable STI' as it is curable in just a few days. Knowing that C.trachomatis was easy to cure even made youth take the risk of having unprotected sex.

"For me it is like unprotected sex can be worth having a C.trachomatis infection. I'll just treat with some antibiotics. Really, it can be worth it. Condom is... well it is not fun."(Interview 2, 22 years old woman).

Thus, negotiating risk of unprotected sex was influenced by the above mentioned interacting factors and often resulted in the decision to engage in unprotected sex. However, decisions made under the influence of alcohol and on sometimes weak grounds, such as trusting a person based on their appearances, did have consequences already on the following day. Most youth expressed that they regretted unsafe sex. Testing however assuaged their feeling of regret.

\section{Testing - "Better safe than sorry"}

The participants expressed that repeat testing was done "just to be on the safe side". Testing after unprotected sex was perceived to be a safe normal sexual practice and an appropriate substitute to using condoms. Testing was thought of as a way of reassuring cleanness; to see if something went wrong and to be able to do something about it. Youth expressed perceiving themselves as 'being careful' by testing repeatedly for C.trachomatis.

"I think safe sexual practices are that you test after unprotected sex. And also maybe that you use a condom, but that's not the most important thing. What's important is that you test when you know you did something stupid" (Interview 4, 22 year old woman).

As described above, anxiety was not present before, or related to the actual episode of unsafe sex. Anxiety however arose afterwards and was related to fear of long term consequences of a C.trachomatis infection, but foremost anxiety related to the risk of spreading C.trachomatis and gaining a bad reputation as a result of this.

Testing to avoid social stigma related to a possible C.trachomatis diagnosis.

Through the analysis it became clear that the social consequences of C.trachomatis were considered much more serious than the possible medical consequences. This was found to be a strong driver in the process of testing and re-testing. The aspect of shame related to infecting someone with C.trachomatis was identified in all interviews. Feelings of shame were present already in the waiting room of the YHC. Just being there suggested that you might have done 'something' and that you were most certainly there to test. To meet a friend in the waiting room was considered to increase feelings of shame and anxiety.

The discussions with the participants also revealed that infecting someone else was considered worse than being infected oneself. The shame associated with risk of spreading the disease varied depending of the level of closeness that the informant had with the sexual partner. Whereas there was no or little shame in spreading C.trachomatis to someone unknown, it would be very shameful to infect someone within a close circle of peers, i.e. a friend or a regular partner. This generated high levels of anxiety as the informants perceived strong negative consequences for their social life such as isolation and a "bad reputation" among their peers.

"To infect someone is probably the most embarrassing thing you can do. People will see you as revolting. It's like this; if a girl infects a guy he will see her as dirty. He might call her a whore. And that's a reputation that you are stuck with." (Interview 8, 20 year old woman).

Another related aspect that generated anxiety was the YHC standard procedure of contacting previous sexual contacts for screening purposes. It generated anxiety because, although contact tracing is meant to be anonymous, it was considered not to be so. A general opinion was that you always could figure out who reported you to the authorities. Interestingly this anxiety could lead to increased use of condom with a friend or with someone you might want to start a relationship with. Condoms could on the other hand be ignored on a one-night stand as the social consequences of C.trachomatis infection were expressed to be non-existent with someone outside your own circle of friends.

\section{Testing to avoid long term medical consequences}

A common perception among our interviewees was that having untreated C.trachomatis for a long time can lead to severe health consequences. However, there was a variation in their understanding of what consequences C.trachomatis could lead to, and an uncertainty of the duration one needed to have harboured C.trachomatis before such sequelae occur. It was however a prevalent opinion that the sooner one discovers C.trachomatis the better it is. Participants expressed that the long-term consequences can be avoided or minimized by frequent testing.

"Before a test there is of course some worry. But I know since I've been so good at testing regularly, it is not the same fear. This is how I see it; if I had only tested once per year then the chance of me having something during a longer period is greater. If that was case then I would 
be more worried. But since I have done it regularly I am calmer. I feel like if I have it then I take my antibiotics and then I'm cured." (Interview 6, 19 year old woman).

\section{Negative test result - false security}

A negative test result was seen as confirmation of the ability to choose a trustworthy "clean" sexual partner. The informants recognised that they had been careless in having sex without condoms; yet they were happy about the possibility of getting away with this risky sexual behaviour without being infected with a STI. While youth were aware that a negative test could provide a false sense of security, it did not affect any change in their risk taking behaviour. On the contrary, a negative test result made them feel invulnerable and confident, reinforcing that there was no need for a change in behaviour. Hence, negative testers continued to have unprotected sex. Repeat negative tests were even reported to make one neglect the importance of protected sex. If unprotected sex has no consequences, they believed there was no need to change behaviour.

"Since I never got anything (an STI) then it was well, I'll do it unprotected. I still understand that I could get something, but I have become a little foolhardy. I have become self-confident. Or maybe self-confident is not a good word but I don't know. Stupid really, I never experienced any consequences and so it (the possibility of consequences) became more and more distant. And now I count on the test to be negative. If it would be positive I would like, oh! I do understand that it could turn out positive but I have gotten used to a negative result." (Interview 13, 21 year old man).

\section{Positive test result - "a quick fix"}

A positive test was constructed as a consequence of one's careless behaviour. It originated from several responses that ranged from identifying it as a "wake-up call", causing some short term behavioural change, to no change at all. Within this spectrum of responses, the dominant conceptualization was that C.trachomatis infection was "a quick fix" meaning that the infection can easily be cured with a short round of antibiotics.

"I want to say I would change my behaviour after a positive test, but I don't know....It would not be fun if you were here for the third time and had a positive Chlamydia. But after having it once, and then you get cured pretty easy, then you would just be like...ah! I mean it's hard to take it seriously (Chlamydia). I know it is serious, but...Do you see what I mean?" (Interview 9, 21 year old man).

This dominant response reiterates the perceptions described in our first category where C.trachomatis infection was not perceived as serious as other STIs such as herpes, HPV or HIV. Consequently, a positive
C.trachomatis test required a "quick fix" but did not merit a long term behavioural change in condom use patterns.

\section{Factors facilitating re-testing behaviors}

The participants expressed no embarrassment testing and re-testing related to the actual test and the encounter with the staff. All interviewees had good experiences from the YHC. Feeling safe and well received at the clinic were important.

It is very easy (testing for C.trachomatis). Super easy and super smooth. Nice to have it done, comfortable that it is for free. It is a very very easy process. (Interview 7, 19 year old woman).

The easy accessibility to the YHC, the flexible opening hours, and the free service offered were perceived as facilitating overuse of the services. Easy access was thought to make youth take the risk of having unprotected sex. While one person said that it would not be worth having unprotected sex if the test would cost money, no one else believed that a fee of a C.trachomatis test would decrease sexual risk taking or increase condom use among youth. Quite the opposite was expressed; a cost would lead to fewer tests and consequently to more infections.

You don't want to stand there, like 2 days before payday and just, I really need to go and test but I don't have the money right now. Those situations... like, you don't have to deal with those. So I think that (free of charge) contribute a lot... that many go and test. And do it regularly. (Interview 3, 20 year old woman).

\section{Discussion}

Our findings show that testing repeatedly for C.trachomatis is a process driven by the interaction between the informants' needs, health beliefs about C.trachomatis and environmental factors such as the characteristics of the Swedish Health Care System. Repeated testing was driven mainly by the informants' fears of the social consequences (stigma, exclusion or humiliation) of spreading the disease among their close group of peers and by their conceptualization of repeated testing as a preventive measure replacing condom use. In the following, we will discuss our main findings using Andersen's Phase four Model of Health Service Utilization [20].

\section{Social stigma and the need for C.Trachomatis re-testing}

Anderson [20] proposes that one of the main drivers of health service utilization is the population's need for specific services and this is clearly the case in our study. Our study participants expressed a strong need to visit the $\mathrm{YHC}$ as testing repeatedly would reduce anxiety related to the social consequences. While the role of stigma in relation to STI is well known, literature has 
mostly described stigma in relation to accepting or rejecting STI testing [32-34]. Testing and re-testing to avoid social stigma has not been previously reported.

Our finding can have important implications for C.trachomatis prevention. While it is important not to shame youth in relation to sexual activity and not further stigmatize STI, our results can be used to inform primary preventive strategies. Youth in our study expressed very strong feelings of regret related to unprotected sex and the anxiety of spreading the infection. Hence, strengthening youth in their decision to use a condom in relation to protect self-respect and reduce anxiety is a way forward. As previously been reported in a Spanish study, gain-framed messages i.e. emphasizing the benefits of behavioral change, can increase condom use [35]. Consequently, focusing on the social benefits of protected sex could be a more effective way to address the issue for the youth community.

It is important to highlight that the youth in our study also expressed a need for visiting the YHC repeatedly as they continued to expose themselves to risk of contracting STI although they were aware of the possible long term medical consequences of C.trachomatis i.e. infertility. This finding is in line with other studies reporting that STI knowledge does not translate into increased condom use [36, 37].

\section{Health beliefs and re-testing for C.Trachomatis among the youth}

Health beliefs influence the need for and utilization of health services [20]. In our study we found that two specific health beliefs: "C.trachomatis is a quick fix and C.trachomatis is not a serious infection", promote both risky sexual behavior and the need for repeated testing.

The conceptualization of C.trachomatis as a mild and easily treatable disease might explain why young people in Sweden express moderate concerns about STI diagnosis and perceive themselves at little risk of contracting STI $[38,39]$. In addition, it might explain why we found that neither a positive nor a negative C.trachomatis diagnosis led to long term preventive behavioural change. Previous studies have indicated similar trends. For example, one US study showed that condom use improved after a positive STI test but reverted after 3 months [40].

Our findings also highlight that, for our informants, testing negative for C.trachomatis provided a false sense of security that validated their choice of sexual partners and their unsafe sexual behavior. This is in line with previous studies reporting that youth who tested negative for STI tended to increase the number of sexual partners, the number of unprotected intercourses [12] and were less likely to use a condom 1 year after testing [13]. Clearly, as also described elsewhere [13], a negative result test seemed to inhibit the participants' behavioral change.
Health beliefs about C.trachomatis are thus important to understand in relation to the success of the screening program and primary preventive strategies. According to our finding expanding existing testing services alone might not make youth adopt safer sexual behaviour. The "quick fix" notion might in fact have the opposite effect on sexual risk taking. Challenging this quick fix notion could be important to promote preventive sexual behavior.

\section{The environment - The Swedish health care system}

The process of repeatedly testing for C.trachomatis was not an isolated process driven just by the individual but was also facilitated by the characteristics of the Swedish health care system. Youth have access to a system that assures free testing, free treatment and easy geographical access to health services [26]. While the YHC is a wellestablished part of Swedish health care, access to youthfriendly services for sexual and reproductive healthcare varies widely between countries [41, 42]. Evaluation and comparison of the effect of youth-friendly clinics on health outcomes such as teenage pregnancy and STI prevalence are thus difficult to assess on a global level, furthermore reporting of the above events are often inadequate [42]. However, the Swedish approach of easy access to the YHC, while commendable should be critically evaluated in terms of its focus on preventive work with regard to STIs. STI prevalence in the youth population might indicate that more can be done in this regard.

\section{Re-testing: A "safe approach" to "unsafe sex"}

Our analysis showed that the interaction between the aforementioned factors has translated into specific health behaviour. Youth in our study seemed to have found a "safe approach" to "unsafe sex". Testing was looked upon as a normal procedure after unsafe sex, a substitute to using condoms. We have not found other studies that report similar findings in this context. It can of course be argued that testing after unprotected sex is better than not testing after unprotected sex. The positive side of this behaviour is that infections are found and treated, partners are notified, and the transmission chain is interrupted. While this is not disputed, testing repeatedly for C.trachomatis allowed youth in our study to continue their sexual risk-taking. As described elsewhere, in the context of HIV prevention, repeat testing allows continued high-risk sexual behavior by confirming that past and current behaviors are safe [43]. Findings from our study indicate similar relationship between repeat testing and sexual risk-taking. This stresses the need for focusing on primary preventive strategies. Furthermore it is clear that young people must be involved in the solutions to halter the epidemic of C.trachomatis in Sweden and elsewhere. 


\section{Limitations}

One limitation includes the method used; in-depth interviews on a sensitive subject could prevent participants from answering truthfully. The interviewer is also a clinic based midwife and it is possible that youth felt intimidated by this or even forced to answer the questions posed during the interview in a particular way. However, we used several strategies to avoid these pitfalls - anonymity was repeatedly assured, the interviews were held in homelike private rooms and the interviewer were dressed in everyday casual clothes, not in the work uniform. To avoid preconceptions and assumptions that could affect the interpretation of the data, each step in the analysis process was done by two researchers with different background. By continuously reflecting on the relationship to the respondents and the subject itself, misinterpretation of the data was thought to be avoided. Trustworthiness of the data was amplified during the interview by the interviewer summarizing the responses to the participant who could confirm or not confirm the accuracy. Furthermore the findings in the present study were triangulated by findings in a subsequent, yet unpublished study [44].

\section{Conclusions}

Our study showed that testing repeatedly for C.trachomatis is a process driven by the interaction between the young peoples' health beliefs, their conceptualization of re-testing as a replacement for condom use and their the fear of negative social consequences of infecting a close peer.

Testing services are key elements needed for C.trachomatis prevention. However, they must not be perceived as a replacement for safe sex. Testing services must therefore be complemented with a much stronger emphasis on safe sex, especially for those who attend the clinic repeatedly. Otherwise, the easily accessible testing services risk counteracting their purpose.

Youth perceptions and beliefs about C.trachomatis can be used as triggers for behavioural changes. Health interventions targeted to the risk group of repeat testers should appeal to their motivation to reduce anxiety related to unprotected sex i.e. avoiding possible social stigma. These should guide the development and evaluation of appropriate interventions to increase condom use.

\section{Additional file}

Additional file 1: Interview guide Youths. (DOC $31 \mathrm{~kb}$ )

\footnotetext{
Abbreviations

C.trachomatis: Chlamydia trachomatis; HIV: Human Immunodeficiency Virus; HPV: Human Papilloma Virus; STI: Sexually Transmitted Infection; YHC: Youth Health Clinic
}

\section{Acknowledgements}

The authors would like to thank the operating managers of the $\mathrm{YHC}$ in Stockholm County for giving their consent to the study. We would like to also like to thank the midwives at the different $\mathrm{YHC}$ for invaluable assistance in recruiting participants to the study. We would especially like to express our appreciation and thanks to the youth who participated in the study and shared their views on such a sensitive subject.

\section{Funding}

The project was funded by FORTE: Swedish Research Council for Health, Working Life and Welfare. The funders had no role in study design, data collection and analysis, decision to publish, or preparation of the manuscript.

\section{Availability of data and materials}

The data used and analyzed in the current study is available from the corresponding author on reasonable request.

\section{Authors' contributions}

AN was responsible for the study design, collection of data, analysis and drafting the manuscript. MS was responsible for study design, analysis and critically revising the manuscript. ADC and KGD was responsible for study design and critically revising the manuscript. All authors have read and approved the final version of this manuscript.

\section{Ethics approval and consent to participate}

Written informed consent was obtained from each participant. Participation was voluntary, confidentiality was assured and each interviewee was informed that they could withdraw from the study at any time. The participants were informed that the interview would contain questions about sexual health and that might be perceived as an invasion of their privacy. The research protocol was approved by the Stockholm Regional Ethical board (reference number 2013/1399-31/2).

Consent for publication

Not applicable.

\section{Competing interests}

The authors declare that they have no competing interests.

\section{Publisher's Note}

Springer Nature remains neutral with regard to jurisdictional claims in published maps and institutional affiliations.

\section{Author details}

${ }^{1}$ Department of Women's and Children's Health K6, Karolinska University Hospital Solna, 17176 Stockholm, Sweden. ${ }^{2}$ Department of Public Health Sciences, Karolinska Institutet, Tomtebodavägen 18 A, 17177 Stockholm, Sweden.

Received: 15 June 2017 Accepted: 3 November 2017

Published online: 15 November 2017

\section{References}

1. ECDC: European Centre for Disease prevention and Control; Chlamydia Contrl in Europe: literature review. In. Retrieved 16.02.16 from: https://ecdc. europa.eu/sites/portal/files/media/en/publications/Publications/chlamydiacontrol-europe.pdf; 2014.

2. National statistics of Chlamydia infection [http://www. folkhalsomyndigheten.se/folkhalsorapportering-statistik/statistikdatabaseroch-visualisering/sjukdomsstatistik/klamydiainfektion/].

3. Herrmann B, Egger M. Genital chlamydia trachomatis infections in Uppsala County, Sweden, 1985-1993: declining rates for how much longer? Sex Transm Dis. 1995;22(4):253-60.

4. ECDC: European Centre for Disease prevention and Control; Guidance on chlamydia control in Europe - 2015. In. Retrieved 21.03.16 from: https://ecdc. europa.eu/sites/portal/files/media/en/publications/Publications/chlamydiacontrol-europe-guidance.pdf; 2015.

5. Center for Disease Control and prevention US Government: Sexually Transmitted Diseases Treatment Guidelines, 2015 In.; 2015. 
6. LaMontagne DS, Fenton KA, Randall S, Anderson S, Carter P. Establishing the National Chlamydia Screening Programme in England: results from the first full year of screening. Sex Transm Infect. 2004;80(5):335-41.

7. Low N. Screening programmes for chlamydial infection: when will we ever learn? BMJ. 2007;334(7596):725-8.

8. The Government of Sweden: National Strategy against hiv/aids and other infectious diseases, 2005/06:60. [Nationell strategi mot hiv/aids och vissa andra smittsamma sjukdomar]. In. Retrieved 09.09.16 from: https://data. riksdagen.se/fil/6B17763D-888B-4445-B0A9-6DFADE78D5D8; 2005

9. The Swedish Parliament: [Smittskyddslagen Svensk Forfattningssamling 2004:168] Law of Infectious Diseases Control. In. Retrieved 08.09.16 from: http://www.riksdagen.se/sv/dokument-lagar/dokument/svenskforfattningssamling/smittskyddslag-2004168_sfs-2004-168; 2004.

10. Stockholm County Council: Action Plan STI/hivprevention 2009-2013. In. Retrieved 10.05.15 from: http://www.sll.se/Global/Landstinget/Styrandedokument/Karnverksamhet/halsa-vard-vagledande-handlingsprogram-stihivprevention.pdf; 2009.

11. Nielsen A, Marrone G, De Costa A. Chlamydia trachomatis among youth testing behaviour and incidence of repeat testing in Stockholm County, Sweden 2010-2012. PLoS One. 2016;11(9):e0163597.

12. Sznitman SR, Carey MP, Vanable PA, DiClemente RJ, Brown LK, Valois RF, Hennessy M, Farber N, Rizzo C, Caliendo A, et al. The impact of communitybased sexually transmitted infection screening results on sexual risk behaviors of African American adolescents. J Adolesc Health. 2010;47(1):12-9.

13. Soetens LC, van Benthem BH, Op de Coul EL. Chlamydia test results were associated with sexual risk behavior change among participants of the chlamydia screening implementation in The Netherlands. Sex Transm Dis. 2015;42(3):109-14

14. Clark LR, Brasseux C, Richmond D, Getson P, D'Angelo LJ. Effect of HIV counseling and testing on sexually transmitted diseases and condom use in an urban adolescent population. Arch Pediatr Adolesc Med. 1998;152(3): 269-73.

15. Kabiru CW, Luke N, Izugbara CO, Zulu EM. The correlates of HIV testing and impacts on sexual behavior: evidence from a life history study of young people in Kisumu, Kenya. BMC Public Health. 2010;10:412.

16. Dieffenbach CW, Fauci AS. Universal voluntary testing and treatment for prevention of HIV transmission. JAMA. 2009;301(22):2380-2.

17. Leval A. Assesessing infection risk and evaluating prevention strategies in the era of HPV vaccines. Doctoral thesis. Department of Medical Epidemiology and Biostatistics, Karolinska Institutet. Stockholm: Sweden; 2012. p. 2012

18. World Health Organization: Global Health Sector Strategy on Sexually Transmitted Infections 2016-2021 In. Retrieved 10.10.16 from: http://apps. who.int/iris/bitstream/10665/246296/1/WHO-RHR-16.09-eng.pdf?ua=1; 2016.

19. Andersen R, Newman JF. Societal and individual determinants of medical care utilization in the United States. Milbank Mem Fund Q Health Soc. 1973; 51(1):95-124.

20. Andersen RM. Revisiting the behavioral model and access to medical care: does it matter? J Health Soc Behav. 1995;36(1):1-10.

21. The Public Authority of Statistics Sweden: Statistical Yearbook of Sweden 2013, [Tabell 13.7 Sammanräknad förvärvsinkomst, medelvärden efter kön, län och kommun 2010, tkr.] In. Retrieved 06.02.16 from: http://www.scb.se/ statistik/publikationer/OV0904_2013A01_BR_14_A01BR1301.pdf; 2013.

22. Statistics of Chlamydia Infection; Stockholm County Council [http://www. vardgivarguiden.se/globalassets/behandlingsstod/smittskydd/statistik/ klamydia/2012.pdf].

23. The Swedish Parliament: [Hälso- och sjukvårdslag (2017:30)] Health Care Law. In. Retrieved 12 Nov 2017 from: https://www.riksdagen.se/sv/ dokument-lagar/dokument/svensk-forfattningssamling/halso-ochsjukvardslag_sfs-2017-30.

24. Höjeberg P: Ungdomsmottagningarnas eldsjälar. In. Retrieved 03.10.16 from: http://www.fsum.org/fsum/wp-content/uploads/2011/04/fsumhistoria.pdf; 2010.

25. Youth Health Clinic Members Sweden [http://www.fsum.org/?page_id=679].

26. Stockholm County Council: Youth Health Clinics; Annual Report 2014, HSN 1504-D520. In.; 2014

27. Collins KMT, Onwuegbuzie AJ, Jiao QG. A mixed methods investigation of mixed methods sampling designs in social and health science research. J Mix Method Res. 2007;1(3):267-94.
28. Corbin JM, Strauss AL. Basics of qualitative research : techniques and procedures for developing grounded theory. 3rd ed. Los Angeles, Calif: Sage Publications, Inc.; 2008.

29. Kvale S, Brinkmann S. InterViews : learning the craft of qualitative research interviewing. 2nd ed. Los Angeles: Sage Publications; 2009.

30. Charmaz K. Constructing grounded theory. 2nd ed; 2014.

31. UMDAC and Division of Epidemiology and Public Health Sciences DoPHaCM, Umeå Universitet: OpenCode 3.4 Software. In.; 2007.

32. Balfe M, Brugha R, O'Donovan D, O'Connell E, Vaughan D. Young women's decisions to accept chlamydia screening: influences of stigma and doctorpatient interactions. BMC Public Health. 2010:10:425.

33. Barth KR, Cook RL, Downs JS, Switzer GE, Fischhoff B. Social stigma and negative consequences: factors that influence college students' decisions to seek testing for sexually transmitted infections. J Am Coll Heal. 2002;50(4): 153-9.

34. Theunissen KA, Bos AE, Hoebe CJ, Kok G, Vluggen S, Crutzen R, DukersMuijrers $\mathrm{NH}$. Chlamydia trachomatis testing among young people: what is the role of stigma? BMC Public Health. 2015;15:651.

35. Garcia-Retamero R, Cokely ET. Effective communication of risks to young adults: using message framing and visual aids to increase condom use and STD screening. J Exp Psychol Appl. 2011;17(3):270-87.

36. Leval A, Sundstrom K, Ploner A, Dahlstrom LA, Widmark C, Sparen P. Assessing perceived risk and STI prevention behavior: a national populationbased study with special reference to HPV. PLoS One. 2011;6(6):e20624.

37. Shepherd J, Kavanagh J, Picot J, Cooper K, Harden A, Barnett-Page E, Jones J, Clegg A, Hartwell D, Frampton GK, et al. The effectiveness and costeffectiveness of behavioural interventions for the prevention of sexually transmitted infections in young people aged 13-19: a systematic review and economic evaluation. Health Technol Assess. 2010;14(7):1-206. iii-iv

38. The Public Health Agency of Sweden: Ungdomsbarometern, Ungdomar och Sexualitet 2014/15. In. Retrieved 07.10.16 from: https://www. folkhalsomyndigheten.se/documents/sexualitet-halsa/ Uungdomsbarametern-2014.pdf; 2015.

39. Tikkanen RH, Abelsson, J., Forsberg, M.r: Ung KAB09. Kunskap,attityder och sexuella handlingar bland unga. Göteborgs Unviversitet. Institutionen för Socialt Arbete. In: Göteborgs Unviversitet Institutionen för Socialt Arbete. Retrieved 08.09.15 from: https://gupea.ub.qu.se/bitstream/2077/25017/2/ gupea_2077_25017_2.pdf; 2011.

40. Fortenberry JD, Brizendine EJ, Katz BP, Orr DP. Post-treatment sexual and prevention behaviours of adolescents with sexually transmitted infections. Sex Transm Infect. 2002;78(5):365-8.

41. Tylee A, Haller DM, Graham T, Churchill R, Sanci LA. Youth-friendly primarycare services: how are we doing and what more needs to be done? Lancet. 2007:369(9572):1565-73.

42. Part K, Moreau C, Donati S, Gissler M, Fronteira I, Karro H. Group R: teenage pregnancies in the European Union in the context of legislation and youth sexual and reproductive health services. Acta Obstet Gynecol Scand. 2013; 92(12):1395-406.

43. Kalichman SC, Cain D. Repeat HIV testing and HIV transmission risk behaviors among sexually transmitted infection clinic patients. J Clin Psychol Med Settings. 2008;15(2):127-33.

44. Nielsen A. DCA, Salazar M.: A qualitative study among Youth Health Clinic staff in Stockholm Sweden. In.; 2017.

\section{Submit your next manuscript to BioMed Central and we will help you at every step:}

- We accept pre-submission inquiries

- Our selector tool helps you to find the most relevant journal

- We provide round the clock customer support

- Convenient online submission

- Thorough peer review

- Inclusion in PubMed and all major indexing services

- Maximum visibility for your research

Submit your manuscript at www.biomedcentral.com/submit 